\title{
Postdural puncture headache with extensive spread of lumbar- cervical epidural cerebrospinal fluid
}

\author{
Emily E. Sharpe, MD (D) Helena M. Gazelka, MD • Katherine W. Arendt, MD
}

Received: 21 March 2019/Revised: 17 May 2019/Accepted: 19 May 2019/Published online: 4 June 2019

(C) Canadian Anesthesiologists' Society 2019

\begin{abstract}
A 39-yr-old woman experienced inadvertent dural puncture during labour epidural placement at the L3-4 level. After an otherwise uncomplicated vaginal delivery, she developed a headache and severe neck pain without weakness, numbness, or cranial nerve dysfunction. She also complained of an electrical sensation down her spine when flexing her neck, consistent with Lhermitte's phenomenon - generally a sign of demyelination or spinal cord compression but also associated with postdural puncture headache (PDPH). ${ }^{1}$ Magnetic resonance imaging revealed epidural cerebrospinal fluid (CSF) extending from vertebral level C3 to L5-S1 (Figure).

After failed conservative therapy, including a sphenopalatine ganglion nerve block performed on postpartum day (PPD) 2, a fluoroscopy-guided epidural blood patch (EBP) was placed at L2-3 on PPD 3. She experienced a mild pressure paresthesia in her lower back
\end{abstract}

during the injection but with complete resolution prior to leaving the fluoroscopy suite. Subsequently, her PDPH symptoms resolved, including the Lhermitte's phenomenon, and she was discharged home without symptom recurrence.

The amount and pattern of the distribution of extra-axial CSF after inadvertent dural puncture are not well established. ${ }^{2}$ Neither is it known if the extent of the epidural fluid collection changes the patient's risk for complications associated with an EBP or makes differentiating the epidural space from the intrathecal space more difficult. After a trial of conservative therapy (including hydration), medical therapy (non-steroidal antiinflammatory drugs, opioids, caffeine), and/or a sphenopalatine nerve block, an EBP may be helpful for relieving the PDPH - although with fluoroscopic guidance to ensure correct placement in the epidural space.
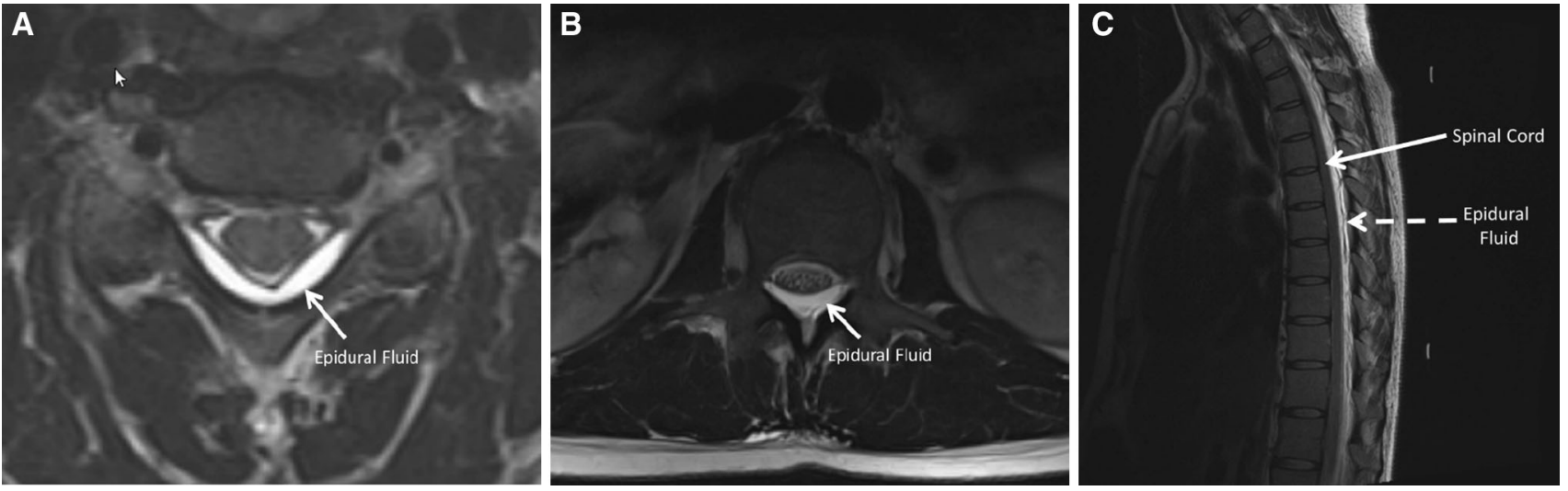

Figure Magnetic resonance images (MRI) of the spine. A) Axial T2weighted images of the cervical C7 region show epidural fluid (white) in a dorsal location. B) Axial T2-weighted image of the lumbar L1 region shows epidural fluid (white) in both ventral and dorsal locations. The cauda equina is visualized. C) Sagittal T2-weighted image shows epidural fluid (white) throughout the cervical, thoracic, and lumbar regions. The epidural fluid collection has displaced the thecal sac and spinal cord anteriorly

E. E. Sharpe, MD $(\bowtie) \cdot$ H. M. Gazelka, MD .

K. W. Arendt, MD

Department of Anesthesiology and Perioperative Medicine,

Mayo Clinic College of Medicine, Rochester, MN, USA

e-mail: Sharpe.emily@mayo.edu 
Conflict of interest None declared.

Editorial responsibility This submission was handled by Dr. Hilary P. Grocott, Editor-in-Chief, Canadian Journal of Anesthesia.

Funding Support was provided solely to the authors from institutional sources.

\section{References}

1. Obray JB, Long TR, Brown MJ, Wass CT. Lhermitte sign associated with postdural puncture headache in a parturient. Anesthesiology 2003; 98: 786-8.
2. Vakharia SB, Thomas PS, Rosenbaum AE, Wasenko JJ, Fellows $D G$. Magnetic resonance imaging of cerebrospinal fluid leak and tamponade effect of blood patch in postdural puncture headache. Anesth Analg 1997; 84: 585-90.

Publisher's Note Springer Nature remains neutral with regard to jurisdictional claims in published maps and institutional affiliations. 